\title{
TEACHING AND LEARNING ANALOGUE ELECTRONICS IN UNDERGRADUATE COURSES: PRELIMINARY FINDINGS FROM THE ETL PROJECT
}

\author{
N. J. Entwistle, A. Hamilton, R. G. Kelly, J. B. Nisbet, \\ University of Edinburgh \\ R. Chapman, G. Hayward, A. Gachagan, \\ University of Strathclyde \\ E-mail: Noel.Entwistle@ed.ac.uk
}

\begin{abstract}
This paper describes ongoing research into the teaching and learning of analogue electronics in three course units at two research-intensive universities. It draws on students' experiences of teaching and learning in analogue course units to explore the nature of the learning they were undertaking and examines the teaching-learning activities they found most supportive of their studying.
\end{abstract}

\section{KEYWORDS}

University teaching, student learning, improving learning, electronic engineering, universities

\section{BACKGROUND TO THE RESEARCH}

The previous paper described the methodology for the ETL project. This paper focuses on the work carried out in two of the departments of electrical and electronic engineering in our sample, while the following two papers focus on the other two departments. The two departments described in this paper are in research-intensive universities, while the others were in a post-1992 university and a college of further education.

From initial discussions with our Subject Adviser, it was decided to focus, as far as possible, on just one area of electronic engineering. As topics in analogue electronics were often found to be difficult by students, that was the area chosen. Colleagues teaching analogue in three departments were approached and those willing to collaborate with the project for up to two years were chosen, providing six different settings in which analogue was being taught.

Both departments chosen for this paper teach analogue throughout four-year BEng courses, with most of the units being compulsory. We decided to concentrate on two second-year course units and one third-year unit in which very similar collaborative initiatives were developed. As already explained in the previous paper, the data collected included interviews with staff and groups of students, as well as questionnaires given to students towards the beginning and the end of each unit. Overall, the research staff collected both questionnaires from 140 students in these three units in the first year of the collaboration (larger numbers completed one or other of them), with 35 students also being interviewed. In the second year 125 students filled in both questionnaires and a further 28 students were interviewed.

Our report of the analysis of the extensive data sets begins by looking at what staff were expecting students to learn and the general approaches to teaching that were adopted. Thereafter, we look at differences between the three units, both in the ways in which students went about their studying and in their reactions to the teaching-learning environments they had experienced. Full qualitative analyses of the interviews are being carried out, but here it is possible only to provide indicative extracts from the preliminary work to illustrate our findings. From these analyses, we identified aspects of the teaching and learning activities that students believed had helped or hindered their learning and discussed a 'collaborative initiative' with staff, designed to provide greater support for learning.

None of the analyses reported below can individually be taken as providing definitive evidence due to the selfreport formats used or limitations in the size and nature of the samples. The results reported should be treated as indicative, but where similar conclusions emerge from the different methods of data collection, these can be treated with more confidence. Taken together, and looked at in relation to findings from other course units included in our study which have a good deal of commonality, it is possible to build up a fairly convincing picture of what students find most useful in helping them to understand analogue electronics. The analyses have yet to be completed for the full sets of data and so the paper is reporting work still in progress. 


\section{WAYS OF THINKING AND PRACTISING}

One of the main purposes of the TLRP programme and our project is to enhance high quality learning. We have been using the idea of ways of thinking and practising in the subject (WTPs) to provide a general term that can then be described specifically within each subject or topic area.

In our initial discussions with staff and interviews with students, we began by exploring the nature of topics within analogue electronic engineering. Previous research had suggested that one of the specific difficulties students encounter in electronics is that they are faced with contrasting representations or models of a circuit the actual circuit, the circuit diagram, simplifying transforms of it, algebraic solutions, and computer simulations

${ }^{1}$. Students have to move between these different representations in solving problems or designing circuits and they also need to understand the function of a circuit in both practical and theoretical ways - the engineering applications and the physics of how it behaves.

In analogue electronics, one additional difficulty seems to be that understanding involves both analytic skills and an 'intuitive' grasp of circuit characteristics - intuitive in the sense that the characteristics of analogue circuits are less transparent and predictable than digital ones. Students thus have to build up substantial experience of the properties of many different kinds of circuit before they can 'see' what lies behind any new circuit diagram they meet or can decide what type of circuit will be required in a design problem.

Understanding electronic circuits thus involves a combination of intuition derived from experience, detailed analysis using problem-solving skills that involve algebraic knowledge and dexterity, and imagination in designing new circuits. This combination of skills, not surprisingly, creates more difficulty than other areas of the curriculum. Staff and students alike explained that a rather different way of thinking was required for analogue compared with digital, one which many students initially found it more difficult to acquire. As one undergraduate student commented:

I think it requires a different kind of mindset than digital, which seems to be more to do with computer science. For analogue, I think it is much more mathematical and analytical. Even just a little difference in a circuit can make a big difference to how it operates, so you have to realise that and go back to first principles and work out how it works again.

\section{TEACHING AND LEARNING ANALOGUE}

There was substantial similarity between the two departments in how the skills in thinking about analogue circuits were developed. Lectures introduced the theoretical ideas underlying various types of analogue circuits, their functions, and the analytic procedures involved in calculating the expected outputs from those circuits. Students were expected to work through a substantial number of circuit problems to build up the ability to recognise the component parts of circuits which combine to produce effects on the input to the circuit. Work on these examples was done partly independently and partly in group tutorials or 'examples classes' where help was provided by the lecturer or tutor. Assessment was based on end-of-unit examination, except in one unit where course work also counted. Students obtained rather little individual feedback on work handed in, although general pointers were provided on performance in class tests and all course units offered some worked examples through which students could check their own solutions. Laboratory experience was provided within a separate unit in the second-year courses, but it covered all the course units being taught at that time, with no direct match possible with topics being taught in the lectures. It was intended that students who attended the classes and completed the work would have a sufficient grasp of the topics to be successful in the end-of-unit examinations, but failure rates proved disappointingly high at the first sitting in all three units during the first phase of the project.

Although the types of teaching and the assignments were very similar across the three units, interviews with the staff suggested that there were marked differences in the way they thought about the subject, and those were, to some extent, reflected in the teaching. Staff who had substantial experience of working in industry were more likely to explain circuits in a functional manner, emphasising design aspects, while other lecturers brought the logical structure of the topic area to the fore, stressing the physical and analytic aspects more strongly. Thus, the teaching of analogue electronics varied in the relative prominence given to analysing existing circuits in mathematical detail and to considering how circuits could be designed to achieve required outputs. There seemed to be no disagreement about the need for both ways of thinking, but the balance between the analytic and the functional does seem to affect how the subject is perceived by students.

When you're sitting and learning in class you tend to be doing circuit analysis and looking at equations whereas when you do anything in the real world or in the lab, you want to go in exactly the reverse 
direction. You want to take an idea and figure out how to implement it rather than have an implementation and figure out how it works... It's in the final stage, when you've already put all this effort and all this design and time into a circuit, you know that the analysis, no matter how hard it is, has to be done.

During the first year of our collaboration with departments, we sought to discover which aspects of the teaching students found most helpful, and which learning had proved most difficult for them. Students generally appreciated the overall quality of the teaching and the efforts that staff were making to help them to understand. Although students expected to find analogue interesting, they did not expect it to be easy; and that was what they found. In both second-year course units, a substantial proportion of the students still reported aspects of analogue to be difficult to understand and suggested ways in which they might be given more support through the teaching arrangements. There was also a more general feeling about the 'sameness' of their learning experience that became de-motivating over time.

[In the learning, you're repeatedly] reading it, hearing it, talking about it, doing it, doing it, doing it... Personally for me that system doesn't work. And I don't know, I guess that's probably why, for first, second and part of third year, it was a case of scraping by. Except for in the case of projects, I've tried to go through the motions; it's the sameness. It's [the same] pattern, and each day is that pattern.

\section{INFLUENCES ON THE LEARNING OUTCOMES}

The next step in our analysis was to establish the relationships that existed among the scales and items from the two questionnaires. The scales describing approaches to studying are made up of several items based on comments made by students and refined through repeated analyses over many years. The other aspects are described by selecting the specific items that are directly relevant to studying electronic engineering.

The analyses of the questionnaire data enabled us to examine links between students' approaches to studying, their perceptions of the teaching experienced, and their academic performance. The pattern of relationships is shown in Table 1. (It should be noted that this analysis contains a larger sample of students drawn from all the course units involved, not just the three that are the focus of this paper.)

The technique of factor analysis used here indicates which scales and items are most closely inter-correlated by identifying separable but inter-related groupings of scales and items. It is probably best to interpret the values reported (factor loadings) as representing the correlation between the factor and the scale or item; the highest loadings are used to interpret the meaning of the factor. Thus, the first factor can be described as students' perceptions of teaching that supports their understanding, with the items having the highest loadings focusing more directly on understanding, encouraged through handouts and other materials, plenty of examples and illustrations, and the close alignment of teaching activities with the declared aims of the unit. The second factor clearly represents deep, well-organised approaches to studying, while the third factor emphasises just one aspect of good studying, namely effort and concentration. But the third factor also shows effort alongside substantial loadings on self-ratings of learning outcomes, with other links to the actual grades awarded and to feelings that the initial knowledge requirements were not difficult. The final factor describes a surface approach linked to a lack of both academic interest and sense of direction.

As the factors are inter-related, it is also important to look at the correlations between them. There are substantial correlations between both the first two factors (teaching perceived as supporting learning and a deep, active approach to studying) and the third factor (level of achievement and effort). The link between perceptions of teaching and the deep approach is, however, much weaker, implying that the effects of teaching and studying, as shown through the student ratings, contribute somewhat separately to student achievement.

Effort, being within the same factor as achievement, seems to be closely bound up with achievement in electronic engineering, although this has not been found to the same extent in the other subject areas.

The overall pattern of relationships is very much in line with previous research, and indeed with general experience, but when taken in relation to other subject areas and in conjunction with the ongoing analyses of interviews in electronic engineering a more differentiated picture is anticipated. 
TABLE 1 - Factor analysis of a selection of scales and items from ETL questionnaires

( $N=172$ undergraduate electronic engineering students in second and third years)

\begin{tabular}{lllllll}
\hline Scales and items & Factor & I & II & III & IV \\
\hline
\end{tabular}

\section{Attitudes towards the degree course}

I want to study the subject in depth by taking interesting and stimulating courses

When I look back, I sometimes wonder why I ever decided to come here.

\section{Approaches to studying}

Deep approach to learning (6-item scale)

Monitoring studying and skill development (4 items)

Study organisation and time management (2 items)

Effort and concentration (2 items)

Surface approach to learning (4 items)

\section{Relative easiness of demands made by course unit}

What I was expected to know to begin with.

The rate at which new material was introduced

The amount of work I was expected to do

\section{Experiences of the teaching provided in the course unit}

I could see the relevance of most of what we were taught in this unit.

I found most of what I learned in this course unit really interesting

How this unit was taught fitted in well with what we were supposed to learn.

The handouts and other materials we were given helped me to understand the unit.

Plenty of examples and illustrations were given to help us to grasp things better.

Staff tried to share their enthusiasm about the subject with us.

Staff were patient in explaining things which seemed difficult to grasp.

It was clear to me what was expected in the assessed work for this course unit

\section{Self-ratings of learning outcomes}

Knowledge and understanding about the topics covered

Ability to think about ideas or to solve problems

Skills or technical procedures specific to the subject

Overall academic progress

\section{End-of-unit summative assessment grade}

\begin{tabular}{|c|c|c|c|c|c|}
\hline & ons & $\mathbf{I}$ & II & III & IV \\
\hline I & Teaching that supports understanding & 1.00 & .19 & .48 & .03 \\
\hline II & Deep active approach to studying & & 1.00 & .45 & -.04 \\
\hline III & Level of achievement and effort & & & 1.00 & .06 \\
\hline IV & Lack of purpose and surface approach & & & & 1.00 \\
\hline
\end{tabular}

Analysis extracted $40.3 \%$ of the variance. Loadings less than 0.19 have been omitted, while those of 0.3 and above are in bold. 


\section{COMPARISONS BETWEEN COURSE UNITS}

Besides knowing how the items and scales interrelate, it was also important to consider differences between the three units on all the main aspects included in the first year of the work with departments. To make clearer what students were actually rating, individual items have been used throughout Table 2 which presents two kinds of comparison. For most of the items, straight comparisons are made between the three courses - two second-year courses and a smaller third-year unit. But the items describing approaches to studying introduce comparisons between the ways students said they were studying before starting the analogue unit and how they studied during that unit. (As these items are derived from well-established general scales, the wordings may not fit ideally with specific study activities undertaken in electronic engineering, but students do seem to be able to interpret them within that context.)

Looking at the ways students described how they were studying before and during the unit, we find that in Courses A and B the students' approaches during the unit were less deep, less organised and more surface, than their general approaches reported at the beginning of the unit. In Course C, however, the first deep item (which provides the clearest indication of a deep approach) suggests a deeper approach in the unit than beforehand, and that is reinforced by a reduced level of surface approach in both those items.

In all three course units students reported putting in less effort than in other units and, from the frequency distributions of individual questionnaire items, it seemed that about a quarter of students in each of the secondyear classes had probably failed to put in the time and effort required to master the techniques. Some of the students indicated in the interviews that they had been deterred by the initial difficulty and so adopted 'surface' coping strategies, rather than engaging with the problems in ways that would lead to understanding. As one student commented:

You work through the tutorial problems and, for the analogue ones, you don't get any answers out of them. You ... sit down and work through the problems and realise you've done all of them wrong ... and you can't see how in the world you got from point 'a' to point ' $b$ '... I tended to [work] blindly. I knew if I [just] followed these steps, then I could come to an answer... We can teach ourselves ... to do an example and have no idea what to do and we scrape by. But we probably would have got great marks had we actually understood what we were doing.

Students need to be convinced that the effort they have to put in is worthwhile and that they will be able to reach solutions to a reasonable proportion of the examples set.

In other research on electronic engineering students, Scheja ${ }^{2}$ suggested that they had experienced delayed understanding, as a result of which they felt they were falling behind in their studies and used a variety of coping ploys to try to catch up. Students in our own study made comments that suggest a similar experience. Of course, some delay in understanding is to be expected, but in this subject area it seems to be substantial. One second-year student commented:

In second year I got a better understanding of what I learnt in first year. Now in third year I've kind of learnt what I was supposed to know in second year. It's a shame that l've never felt that I've learned it in the actual year [it was taught]... When you're being taught something, you're just desperately trying to learn it, and there's not necessarily a whole lot of interest. You're scrambling back to notes [in preparing for the exams], trying to understand the course. [Later on], you do get interested and [then] things start to fall into place.

\section{APPROACHES TO PROBLEM SOLVING}

Students interviewed generally agreed that they were, at first, not at all clear how to solve tutorial problems. They were looking for clear strategies to be offered within the lectures that would guide them more easily towards the solutions. They also wanted more worked examples to be provided to offer additional guidance. Although recognising that worked examples could be helpful, staff were wary of too much 'spoon-feeding' in case it encouraged the mindless following of routines. As we have seen, both staff and students agreed that there was a way of thinking associated with the analysis of analogue circuits that had to be mastered, but achieving this competence proved difficult for a substantial proportion of the students. The marked tendency for surface approaches to be adopted made understanding less likely. It therefore seemed sensible to concentrate our collaborative initiatives on helping to make students more consciously alert to the ways of thinking that were involved, and to explore the reasons for the difficulty experienced more fully in the second year of the work with departments. The initiative agreed was based on the evidence collected in the first year of the collaboration, but also on the more general research on student learning and psychology. 


$\begin{array}{lrrr}\text { Scales and items } & \text { Second year } & \text { Second year } & \text { Third year } \\ \text { Number of students competing first/both/second questionnaires } & \text { Course } \boldsymbol{A} & \text { Course } \boldsymbol{B} & \text { Course } \boldsymbol{C} \\ (\mathrm{N}=94 / 68 / 75) & (\mathrm{N}=68 / 40 / 49) & (\mathrm{N}=54 / 32 / 40)\end{array}$

\section{Attitudes towards the degree course}

I want to study the subject in depth

87.2

5.2

65.3

25.3

33.3

The amount of work I was expected to do

\section{Approaches to studying}

I usually set out to understand what we had to learn

I look at evidence carefully to reach my own conclusion

I've often had trouble in making sense of the things

What l've learned seems unrelated bits and pieces...

I have generally put a lot of effort into my studying

I'm quite systematic and organised in my studying

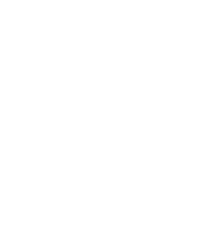

deep

$75.0 \quad 57.4$

surface

$25.0 \quad 61.8$

surface

$11.8 \quad 23.5$

$60.3 \quad 51.5$

before during

77.9

61.1

14.7

29.6

95.672 .1

71.4

62.5

46.9

72.5

34.7

52.5

\section{Experiences of the teaching provided in the course unit}

How this unit was taught fitted in with what we were supposed to learn.

I could see the relevance of most of what we were taught in this unit.

I found most of what I learned in this course unit really interesting

Plenty of examples illustrations were given to help us to grasp things

Staff tried to share their enthusiasm about the subject with us.

89.3

91.8

81.3

81.6

Staff gave me the support I needed to help me complete the set work

Talking with other students helped me to develop my understanding

\section{Self-ratings of learning outcomes}

Knowledge and understanding about the topics covered

61.2

95.0 


\section{EXPERT AND NOVICE LEARNING}

There is a substantial research literature in psychology on how novices differ from experts in the problemsolving skills required in employmentl settings, and how such skills can best be developed ${ }^{3}$. Although problemsolving in electronic engineering clearly has aspects which are specific, there should still be elements in common with professional contexts. The main features highlighted in this psychological research were found in the teaching of analogue electronics, although not always in a fully developed form.

All the units gave students a large number of examples chosen to cover the most salient differences in the problems, but novices also have to be encouraged to look for recurring patterns and to develop systematic strategies. While students asked to be given clear guidelines for solution strategies, lecturers were wary of doing that. They wanted students to realise that mindless following of such guidelines would not get them very far in analogue electronics. The psychological research suggests that, in the early stages, novices do need the 'scaffolding' provided by set routines or strategies, with that support gradually being removed as students develop in experience and confidence.

The metaphor of scaffolding is appropriate because scaffolding is an external structure that supports another structure under construction. As the new structure is completed and capable of standing on its own, the scaffolding is removed. ${ }^{4}$

Hearing experts solve problems out loud is also important for novices as it makes explicit the ways of thinking used by experts in reaching solutions: staff did this to some extent but students wanted rather more of this activity. And discussions among novices also helps, as previous research suggests, both in engineering ${ }^{5}$ and in other subject areas ${ }^{6}$. Focusing on the processes of problem-solving through group work does prove helpful: students we interviewed had generally not been given such opportunities in class, although some of them had formed self-help groups in their own time. Finally, the research suggests ways of encouraging novices to internalise their reasoning processes, for example, by making notes about mistakes made, and better ways of tackling the problems. Some students seemed to be doing this, but others were not working so systematically.

\section{THE COLLABORATIVE INITIATIVES}

All the teaching staff agreed to explore ways of encouraging more students to use a deep approach by focusing explicitly on the processes and strategies of problem-solving. Besides putting a strong emphasis on explaining the processes in lectures and tutorials (as was already happening), it was decided to introduce other student activities during the second year of the collaboration.

As a way of encouraging students to think more consciously about problem solving, students were asked to carry out their work on problems in a tutorial 'log-book' which staff could look at during tutorials. They were encouraged to note down corrections to their attempted solutions in ways that would draw attention to where they had gone wrong, and what they should have done. Besides making their thinking explicit, the log-book also drew their attention to the need to build up a substantial number of solutions there. It was also agreed, where possible, to get students to work together in small groups to discuss the problem-solving processes both in classes and in their own time.

\section{IMPLEMENTING THE INITIATIVES}

In the event, unexpected difficulties prevented a full implementation of the initiative in two of the units. The start was substantially delayed in Course A due to a prolonged illness of the lead lecturer, and was only used briefly in Course B; it was fully implemented only in Course C. Questionnaires given at the end of each unit contained additional questions specifically about how much the students believed that the various teaching-learning activities on the unit had contributed to their learning and understanding. In addition, students were asked to add their own comments about what helped and hindered, and these will contributed to the eventual conclusions.

Table 3 shows the mean and standard deviations on seven-point scales for the samples obtained in the collaborative phase of the project, indicating how much each of the aspects was believed to contribute. Unit A was perceived by the students as being very strong in the provision of worked examples and in enabling students to work on problems on their own, supported by effective help in tutorials, although the explanations in lectures were rated less highly. Unit B was almost the converse, with the explanations appreciated, but worked examples and the tutorial help less highly regarded. There was considerable variation in the rating of tutorials, however, as students from different degree courses (such as mechanical engineering and computing) reported contrasting experiences. In neither unit was the feedback on work submitted felt to be very helpful, and that seems to have been a general reaction from students across most of the units we have looked at. 
The use of log-books was the main innovation in the teaching in all three units and it was hardly surprising that students rated that activity highly only where it had been fully implemented. In the interviews, reactions to the log-books varied. Initial reservations about an additional task were expected, and found, but there were also positive comments. Students appreciated having all their workings together and found their own comments helpful when reviewing their workings.

TABLE 3 - Mean scores of ratings of relative helpfulness of teaching-learning activities

\begin{tabular}{lccc}
\hline & \multicolumn{3}{c}{ Mean scores on a $1-7$ scale } \\
Teaching-learning activity & Course A & Course B & Course C \\
& Mean (SD) & Mean (SD) & Mean (SD) \\
& N = 59 & N = 73 & N = 27 \\
\hline The way diagrams presented & $5.0(1.3)$ & $5.3(1.2)$ & $5.9(0.6)$ \\
The way ideas explained in lectures & $4.3(1.6)$ & $5.6(1.2)$ & $5.2(0.8)$ \\
Lecture explanations of problems & $4.2(1.8)$ & $5.8(1.3)$ & $4.9(1.1)$ \\
Worked examples provided & $5.0(1.4)$ & $3.6(2.1)$ & $5.7(1.1)$ \\
Working on problems on own & $5.2(1.3)$ & $4.6(1.5)$ & $5.3(0.9)$ \\
Using the log-book & $4.2(1.7)$ & $4.3(1.5)$ & $5.1(0.9)$ \\
Staff help in tutorials & $5.0(1.7)$ & $4.0(2.3)$ & $5.9(1.1)$ \\
Discussions with other students & $4.8(2.1)$ & $4.7(2.0)$ & $5.0(2.0)$ \\
Feedback on work submitted & $3.5(2.1)$ & $3.6(2.2)$ & $2.6(2.4)$ \\
\hline & $4.3(1.8)$ & $4.2(1.9)$ & not given \\
Class tests and the results & & &
\end{tabular}

Some students also found that they had become more aware of the need to keep up with their work in preparing for the tutorials. A typical comment was:

I got used to writing down all the problems in the log-book and then you can sort of look back and read through it and understand what you have done ... At first l'd just look at a couple of tutorial questions and write down what I thought. But now l've got, like, pages of stuff written down, so I thinkk the logbook now is really important to my understanding.

It was clear, however, that students did not appreciate being told precisely how they should use the log-books, as they develop a way of using them that is coherent with their established ways of studying. And some students had found it difficult to know what type of comments to make: reflection on learning processes does not come naturally and so requires a thorough introduction and substantial help until the idea has been fully grasped.

\section{TEACHING TO ENHANCE STUDENT LEARNING}

The final analysis to date brings us more directly to the main aim of the project - to identify ways of enhancing the quality of student learning. This analysis has brought together all the items in the second questionnaire used to report students' experiences of the teaching with the additional items specific to electronic engineering $(\mathrm{N}=129)$. Three of seven factors extracted described the main differences among the specific items, but these were also linked to a sub-set of the general items. The combination of the two groups of items within each factor 
TABLE 4 - Items defining three factors related to aspects found helpful in learning analogue

Items are presented in the order of the size (above 0.35) of factor loadings within each set of items

Well-organised teaching providing good explanations, examples, emphasising thinking

Items on what helped in learning analogue

The way the lecturer(s) explained how to think about problems

The way ideas and concepts were explained in the lectures

The way diagrams were presented and used in lectures

General items relating to experiences of teaching and learning

Staff helped us to see how you are supposed to think and reach conclusions in this subject

Staff tried to share their enthusiasm about the subject with us

We weren't just given information; staff explained how knowledge is developed in this subject

The course unit was well organised and ran smoothly

The teaching encouraged me to rethink my understanding of some aspects of the subject

We were given a good deal of choice over how we went about learning

How this unit was taught fitted in well with what we were supposed to learn

Plenty of examples and illustrations were given to help us grasp things better

\section{Supporting students' work on tutorial examples}

Items on what helped in learning analogue

The help give by staff as you worked on tutorial problems

Feedback and comments from staff on the work submitted

Worked examples provided in handouts or on the web

The class tests and the results you were given

Working on the tutorial problems on your own

\section{General items relating to experiences of teaching and learning}

The feedback given on my work helped me to improve my ways of learning and studying

Staff gave me the support I needed to help me complete the set work for this unit

The feedback given on my set work helped to clarify things I hadn't fully understood

The different types of teaching (lectures, tutorials, labs., etc.) supported each other well

On this unit, I was prompted to think about how well I was learning and how I might improve

Doing the set work helped me to think about how evidence is used in this subject

I was encouraged to think about how best to tackle the set work

\section{Working collaboratively with other students}

Items on what helped in learning analogue

Group discussions with other students on doing the problems

General items relating to experiences of teaching and learning

Talking with other students helped me to develop my understanding

Students supported each other and tried to give help when it was needed

I found I could generally work comfortably with other students on this uni 
helps to suggest what aspects of the teaching-learning environment analogue electronic students found most helpful in supporting their learning of analogue. The items picked out by these three factors are shown in Table 4.

The first group of items describe teaching that is perceived by the students to be coherently organised and which is seen as providing good explanations and examples, emphasising the need to think more deeply about the subject. The second group described the types of support that students appreciated in working on the examples, while the third indicated the ways in which collaborating with other students had helped.

A tentative suggestion emerging from an overview of the analyses to date is that there are some aspects of the teaching and learning that are logically essential for students to develop an understanding of analogue circuits, while there are others which play a more supportive role in making the students' work easier and more enjoyable. Only if the essential components are well developed, and sufficient of the others are present, will students report substantial satisfaction with their experience and find it relatively easy to develop their understanding. And this conclusion seems likely to apply generally in the teaching of electronics.

The project as a whole is demonstrating the value of using detailed feedback questionnaires, together with group interviews, to describe students' experiences of teaching. In this way it becomes much clearer which aspects of the teaching-learning activities are most appreciated by students as supporting their learning, and interpreting those findings in relation to the explanations provided by staff suggests ways in which current provision may be strengthened. At this stage of the project, these elements in teaching and learning electronics are only gradually becoming clear through the ongoing analyses of interview transcripts. Bringing together the whole set of analyses, and looking at these in relation to the other subject areas, should enable us to describe more clearly what is specific to teaching and learning in electronic engineering in a future article.

\section{REFERENCES}

1. N. J. Entwistle, D. J. Hounsell, C. Macaulay, G. Situnayake, and H. Tait, The Performance of Electrical Engineering Students in Scottish Higher Education, (Scottish Education Department, Edinburgh, 1989).

2. M. Scheja. Contextualising Studies in Higher Education: First-year Experiences of Studying and Learning in Engineering. (Ph.D. thesis, Department of Education, Stockholm University, Stockholm, 2002).

3. R. J. Sternberg, E. L. Grigorenko, and M. Ferrari, M., 'Fostering intellectual excellence through developing expertise', in M. Ferrari (Ed.), The Pursuit of Excellence through Education, (Lawrence Erlbaum, Mahwah, NJ, 2002), pp. $57-84$.

4. C. McCormick and M. Pressley, Educational Psychology: Learning, Instruction, Assessment (Longman, New York, 1997), p.15.

5. D. J. Nicol and J. T. Boyle, 'Peer instruction versus class-wide discussion in large classes: a comparison of two interaction methods in the wired classroom'. Studies in Higher Education, 28 (2003), pp. 457-473.

6. J. B. Biggs, Teaching for Quality at University ( $2^{\text {nd }}$ ed.) (SRHE \& Open University Press, Buckingham, 2003).

\section{ACKNOWLEDGEMENTS}

Besides the authors of the three grouped papers here, and the whole ETL research team mentioned in the first paper, other university teachers contributed to the ideas. We are grateful for the discussions we have been able to hold with Martin Reekie, Les Haworth, and David Renshaw at the University of Edinburgh, and Sherri Johnstone at Durham University. 